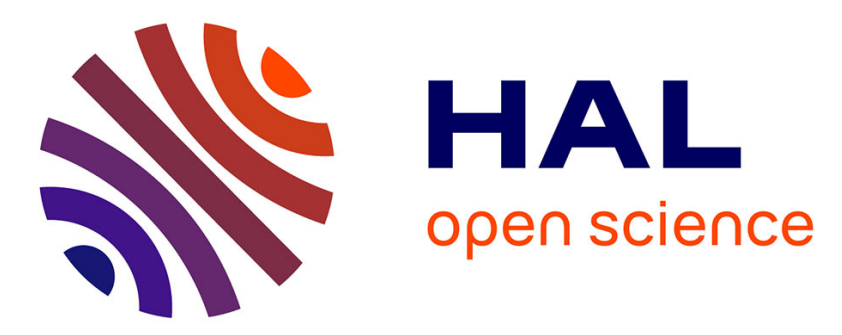

\title{
SPIRAL 2 RFQ prototype first tests
}

R. Ferdinand, A. Caruso, G. Congretel, A. Curtoni, O. Delferriere, A. France,

M. Di Giacomo, D. Leboeuf, J. Thinel, J.C. Toussaint

\section{To cite this version:}

R. Ferdinand, A. Caruso, G. Congretel, A. Curtoni, O. Delferriere, et al.. SPIRAL 2 RFQ prototype first tests. 2005 Particle Accelerator Conference (PAC05), May 2005, Knowville, United States. pp.2488-2490. in2p3-00122905

\section{HAL Id: in2p3-00122905 https://hal.in2p3.fr/in2p3-00122905}

Submitted on 5 Jan 2007

HAL is a multi-disciplinary open access archive for the deposit and dissemination of scientific research documents, whether they are published or not. The documents may come from teaching and research institutions in France or abroad, or from public or private research centers.
L'archive ouverte pluridisciplinaire HAL, est destinée au dépôt et à la diffusion de documents scientifiques de niveau recherche, publiés ou non, émanant des établissements d'enseignement et de recherche français ou étrangers, des laboratoires publics ou privés. 


\title{
SPIRAL 2 RFQ PROTOTYPE FIRST TESTS
}

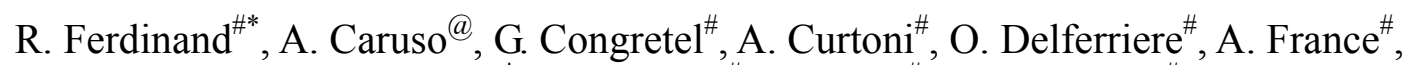 \\ M. Di Giacomo ${ }^{*}$, D. Leboeuf ${ }^{\#}$, J. Thinel $^{\#}$, JC. Toussaint ${ }^{\#}$ \\ \# CEA-Saclay, 91191 Gif-sur-Yvette, FRANCE \\ (a) INFN-LNS, 95123 Catania ITALY \\ * GANIL, 14112 Caen, FRANCE
}

\begin{abstract}
The SPIRAL 2 RFQ is designed to accelerate at $88 \mathrm{MHz}$ two kinds of charge-over-mass ratio, $\mathrm{Q} / \mathrm{A}$, particles. The proposed injector can accelerate a $5 \mathrm{~mA}$ deuteron beam $(\mathrm{Q} / \mathrm{A}=1 / 2)$ or a $1 \mathrm{~mA}$ particles beam with $\mathrm{q} / \mathrm{A}=1 / 3$ up to $0.75 \mathrm{MeV} / \mathrm{A}$. It is a $\mathrm{CW}$ machine which has to show stable operation, provide the request availability, have the minimum losses in order to minimize the activation constraints and show the best quality/cost ratio. The prototype of this 4-vane RFQ has been built and tested. It allowed to verify the mechanical assembly concept (RFQ without any brazing step). The full power was easily injected in the cavity, with no concerns for the RF joints. The paper describes the different achievements.
\end{abstract}

\section{INTRODUCTION}

The SPIRAL 2 extension of the existing GANIL facilities is under detailed study. It will extend the exotic particle productions of the present SPIRAL cyclotron towards heavier elements [1].

The first idea was to use a deuteron beam to induce fission in a uranium target. A specific driver was chosen, and the concept of a superconducting linear accelerator for very high intensity light and medium-heavy ion beams was selected as the best option. The acceleration of deuterons by this driver would achieve the specifications fixed for SPIRAL 2, namely $10^{13}$ fissions per second. The project is in the detailed study phase which has to be finished in October 2004.

The driver is required to accelerate in $\mathrm{CW}$ mode either $5 \mathrm{~mA}$ of deuteron beam up to $40 \mathrm{MeV}$ or $1 \mathrm{~mA}$ of $\mathrm{Q} / \mathrm{A}=1 / 3$ particles to an energy of $14.5 \mathrm{MeV} / \mathrm{u}$. It will be made of two dedicated ion sources, a single RFQ, and 2 families of superconducting quarterwave resonators. This paper describes the RFQ first tests in Istituto Nazionale di Fisica Nucleare (INFN) Laboratori Nazionali del Sud (LNS) in Italie (Catania).

\section{RFQ DESCRIPTION}

The RFQ was fully described elsewhere [2,3]. It is a $\mathrm{CW} 4$-vane RFQ powered at $88 \mathrm{MHz}$. The reader is invited to refer to theses references to understand the mechanical choices leading to this $5-\mathrm{m}$ long design.

The dynamics was calculated by the SPIRAL 2 beam dynamics team in end-to-end Linac simulations. The calculations [4,5] show beam transmission higher than $99 \%$. With all combined errors (mechanical and RF) it has to be higher than $97 \%$ in order to allow hands-on maintenance on the cavity. End-to-end simulations showed very good result for the RFQ. It is not the limitative accelerator component. Nevertheless, a comparative study has been done with the RFQ transport code LIDOS and shows similar results [6]. The beam dynamic design has been verified.

A 1-m long prototype was decided to verify its feasibility and control the construction cost. Under RF power, we had to prove the operation with RF joints between the vanes and the external tube. The final objectives are to verify that the vanes displacement under operation is below the requirements $( \pm 0.1 \mathrm{~mm})$, crosschecked the 3D codes used for the design with online measurement (temperature elevation, deformation, water cooling etc...) and to qualify the vacuum needed for heavy ion acceleration. The tests were planned to be conducted in 4 main steps: The first one, already achieved was to test the cavity at low level in Saclay. The second one, already achieved, was to send the prototype to INFNLNS Catania for high power test with the idea of stressing the RF joins and verifying our ability to power the cavity. It is then planned to tune it with precision ( 8 tuners and end plates) in Saclay and to check in Grenoble the deformations with a second high power test.

\section{FIRST TEST IN CEA-SACLAY}

The prototype is a nice realisation of the DESHORS Company in Brive (France). The measurements gave vane tips globally within $\pm 25 \mu \mathrm{m}$ of their theoretical positions with few points up to $\pm 50 \mu \mathrm{m}$ (measured before the final vacuum test). The RFQ prototype cavity was received from the vendor on July 7, 2004, as most of the other pieces. During the summer time, two complete clean up of the copper parts were performed, the RFQ was assembled and measured (low level RF). The theoretical resonant frequency with the $50 \mathrm{~mm}$ thick flanges is 89.044 MHz. The theoretical Q0 obtained with Soprano is 13970 . It was measured around 12800 at $21^{\circ} \mathrm{C}$.

The tuning capability was tested in Saclay using aluminum adjustable tuners. The observed tuning slope is $+8.65 \mathrm{kHz} / \mathrm{mm}$, in reasonable agreement with the $+7.94 \mathrm{kHz} / \mathrm{mm}$ predicted by the line model. The loaded quality factor remains unchanged $\left(\mathrm{Q}_{\mathrm{L}}=2659\right)$, showing that aluminum slugs do not significantly reduce the cavity Q.

The slope of resonance frequency vs. temperature is founded to be $-1.77 \mathrm{kHz} / \mathrm{K}$, close to the free expansion 
theoretical value of $-1.47 \mathrm{kHz} / \mathrm{K}$. The temperature coefficient of unloaded $\mathrm{Q}$ is $-1.81710^{-3} / \mathrm{K}$, leading to $3.6310^{-3} / \mathrm{K}$ for copper conductivity, close to the $-3.8810^{-3} / \mathrm{K}$ theoretical value.

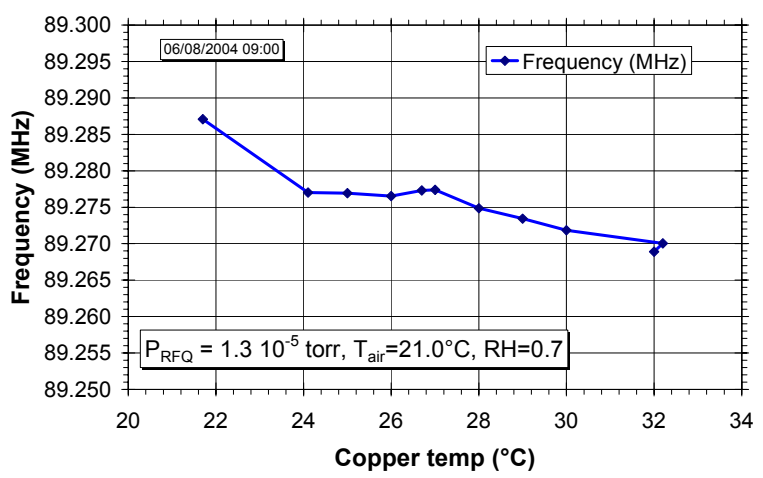

Figure 1: Frequency measurement in Saclay.

\section{INSTALLATION IN CATANIA}

Thanks to the good relationship between GANIL and INFN-LNS, especially in the accelerator field, the collaboration concretization became particularly easy. A 3 weeks test was organized in September 2004 in Catania.

We arrived on August 31, and we were under vacuum on the same day by $5 \mathrm{pm}$. Resonance frequency was shifted by $+17 \mathrm{kHz}$ during vacuum pumping, which is somewhat lower than expected from the variation in air index of refraction. The difference might be due to small geometrical deformations, for instance equivalent to a variation of 1 or $2 \mu \mathrm{m}$ in electrode gaps.

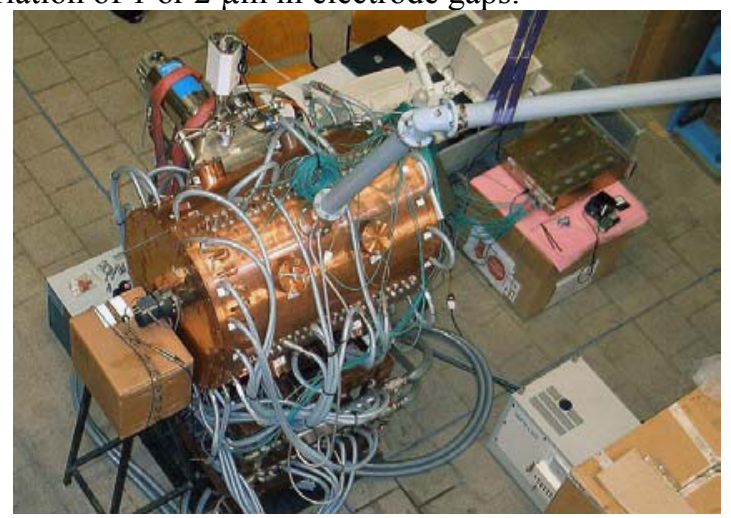

Figure 2: RFQ installation in INFN LNS.

\section{High Power Tests}

High-power tests were conducted with the $50 \mathrm{~kW}$ Power Amplifier (PA) supplied by LNS/Catania. In this configuration, the PA is protected by its own interlock circuit, and the RFQ cavity is successfully fed up to $19 \mathrm{~kW}$ without any problem. Tests in the 20 to $40 \mathrm{~kW}$ range required external PA protection. Various interlock configurations have been tested, using home-made circuits from CEA/Saclay and LNS/Catania. A satisfactory system has been obtained with a PIN diode fast switch, activated when either reflected power or light in the cavity exceeds some preset thresholds. After RF switch-off, the system waits for $200 \mu \mathrm{sec}$ before applying
RF power again with a $10 \mathrm{msec}$ rise-time. With this protection system, the RFQ cavity is powered up without major problem.

The pick-up signal was strictly proportional to the input power up to $31 \mathrm{~kW}$. In the range $31 \mathrm{~kW}$ to $50 \mathrm{~kW}$, the pick-up signal increases slower than input power, ending with a $1 \mathrm{~dB}$ loss at $50 \mathrm{~kW}$. Post-test examinations of RFQ prototype have revealed severe arcing between the pick-up loop and the inner wall of the cylindrical hole where it is inserted, which is a candidate explanation for these high-power losses.

The interlock system behaves properly in the presence of arcing during "normal" cavity conditioning. However, the manually-controlled RF chain is inherently unable to reach any stable operation in a reasonable amount of time, preventing the acquisition of meaningful frequency data, and leading to many undue interruptions of RF.

\section{Vacuum Measurements}

The cavity was pumped by a cryogenic pump. The first vacuum was obtained with a small turbo pump. On the vacuum manifold, 2 vacuum pressure measurements were available: a Pirani/Penning set and a Bayard Alpert measurement. The gas could be analyzed using a residual gas analyzer, in order to identify the possible seal damage and the type of spark.

The vacuum result was globally coherent with the estimated values based on a desorption rate equal to 4.5 $10^{-7} \mathrm{~Pa} . \mathrm{m} . \mathrm{s}^{-1}$, as experimentally observed on a copper plated DTL cavity (IPHI) tests after 100 hours at $40 \mathrm{~kW}$ $\mathrm{RF}$ injection. The static pressure at the end of the tests was better than expected reaching $2.110^{-6} \mathrm{~Pa}$. The viton joins, the only ones available for this first test, were of good quality. The dynamic pressure showed pressure increase, $90 \%$ resulting of $\mathrm{H}_{2}$ desorption. This is less important for the beam losses in operation (light gas). The test of the metallic $\delta$ joins will be performed in Grenoble, next June.

\section{X-Rays Measurements}

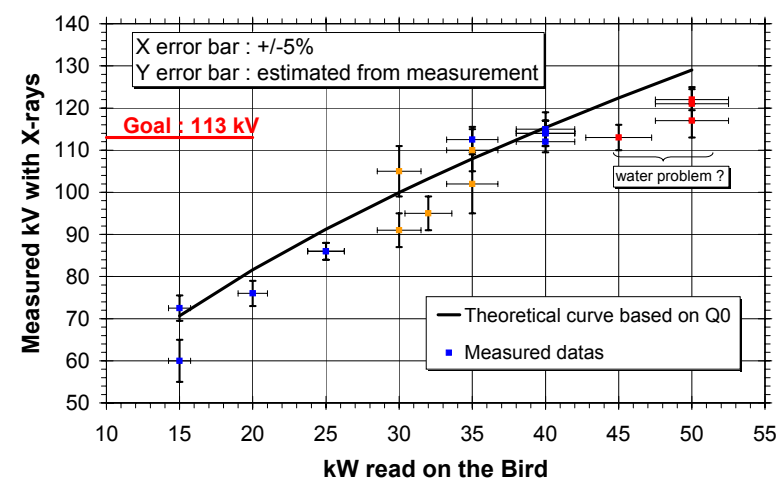

Figure 3: X-rays measured vane voltage on the prototype.

The X-rays measurements allowed correlating the injected RF power and the expected vane voltage. Since the electric field is the important parameter for the beam acceleration, this was the most important measurement of the tests. X-rays were measured in 2 locations, with 2 
types of detectors: Silicium detector and nitrogen cooled germanium detector. The results were similar, and proved the $113 \mathrm{kV}$ achievement.

\section{Water}

Considering different water temperatures, it appeared that it would be easy to limit vane tip displacements by using two different water temperatures. The 2 independent circuits are the external tube circuit and the vane circuit. The 2 circuits will present a difference of temperature depending on the accelerated particles on the final $\mathrm{RFQ}$.

Unfortunately we had no diagnostics on the prototype water flow at the RFQ point. The flow between the different water cooling passages was supposed to be set using hardware-fixed flow regulators. This supposed that the right pressure was present on the water repartition, which was not the case the last two days.

The prototype temperature was verified using 32 thermocouples located on most of the water circuits and typical copper location. Globally, the temperature elevation in the vane and external tube circuits were close to the calculated values.

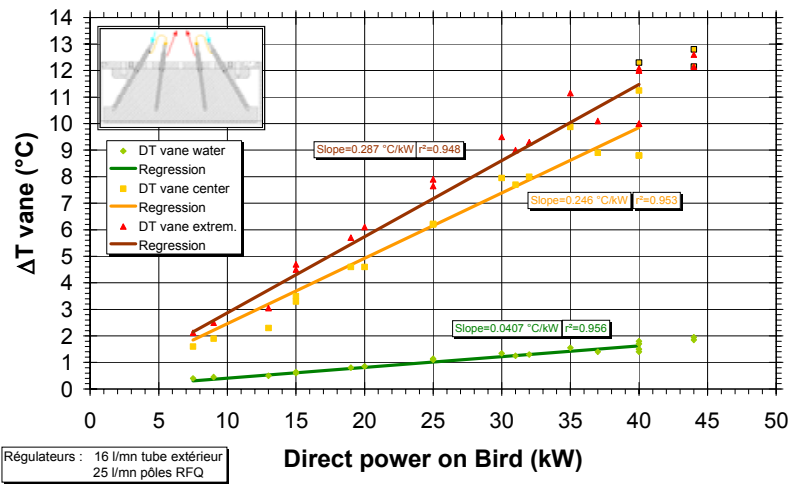

Figure 4: temperature elevation in the vane circuit.

\section{RF Joins}

Very low spark rate was observed. A visual inspection of the internal cavity and RF joins was performed back in Saclay. No significant spark was observed on the copper (except in the pick-up loop). The RF joins seem to be newly installed. The concept of building the RFQ without any brazing step, like a simple mechanical assembly, was validated from the RF join point of view.

\section{Feed Back for the Final RFQ}

The severe arcing observed between the pickup loop and the inner wall of the cylindrical hole where it is inserted will be corrected by an increase of this cylindrical hole. The unfortunate cavity should disappear, as tested back in Saclay. New high power test in Grenoble will allow validating the new design.

The RF power loop reveals to be too big for the 40 to $50 \mathrm{~kW}$ range. Its location was clearly unfortunate and was chosen for practical reasons (insertion of the tuners). The power loop will be located in the middle of the quadrant for the final SPIRAL2 RFQ in order to minimize the dipolar modes.

The test in LNS/Catania revealed that we can probably suppress 2 of the 4 cooling passages in the external tube. The Grenoble test should allow us to validate this point as 2 different circuits will be available with 2 different controlled temperatures. The risk is that the resulting longitudinal temperature elevation in the copper leads in too strong RF perturbation in high power operation. As the tuners reveal to be too small to be sure to correct all possible manufacturing errors, their size will be increased using the space left by removed cooling circuits.

\section{CONCLUSION}

The first high power tests worked very well. Up to $50 \mathrm{~kW}$ was injected in the cavity. The vane voltage goal was achieved. The manual tuning did not allow us to performed a long run test. The next high power tests are scheduled for June 2005, in Grenoble. The long run test might be performed at that time. The cavity has been retuned to optimize the field flatness. Vane displacement and vane temperature elevation will be recorded using different non intrusive techniques (CCD and IR camera measurements) and the vacuum will be validated with the metallic $\delta$ joins.

\section{ACKNOWLEDGMENTS}

We would like to thank again the LNS team for their welcome and the help they provided us. It was the key point for the success of this operation. Special thanks to Danilo Rifuggiato, Antonio Caruso, Antonino Spartà, Daniele Tudisco and Paolo Romano. The run was a rush, and they provided a real help and support.

The SPIRAL 2 RFQ group is grateful to the IPHI team that designed and built the IPHI RFQ [7] and the IPHI DTL hot model for their assistance and participation. Special thanks to P-Y. Beauvais, J. Gaiffier, M. Painchault, G. Bourdelle, and P-E. Bernaudin.

\section{REFERENCES}

[1] SPIRAL and SPIRAL 2 project, http://www.ganil.fr.

[2] R. Ferdinand et al, "SPIRAL 2 RFQ Design", page 2026-2028, Proc. EPAC 2004, Lucerne, Switzerland.

[3] RFQ Final Report, technical note SPIRAL2 EDMS-I004532.

[4] R. Duperrier et al. "Status report on the beam dynamics developments for the SPIRAL2 project", Proc. EPAC 2004, Lucerne, Switzerland, 2023-2025.

[5] "Beam dynamic development for the SPIRAL2 project Final report", EDMS report Id I-004165 and "Start to end errors studies through the SPIRAL 2 linac", EDMS report I-004169.

[6] SPIRAL2 RFQ investigations, I. Shumakov, S. Vinogradov, A. P. Durkin. technical note SPIRAL2, October 2004. EDMS Id I-004677.

[7] P.-Y. Beauvais et al., "Status report on the Saclay High Intensity proton injector project (IPHI)", proceeding of EPAC 2000, p. 283. 